ISSN: 0213-2052 - eISSN: 2530-4100

DOI: http://dx.doi.org/10.14201/shha201836117134

\title{
UN ALTAR CILÍNDRICO A LA VICTORIA EN EL FORO DE LOS BAÑALES DE UNCASTILLO (ZARAGOZA, ESPAÑA) ${ }^{1}$
}

\section{A Cylindrical Altar to the Victory from the Forum of Los Bañales de Uncastillo (Zaragoza, España)}

\author{
Javier ANDREU PINTADO \\ Universidad de Navarra \\ jandreup@unav.es \\ Luis ROMERO NOVELLA \\ Universidad de Navarra \\ 1romero@alumni.unav.es
}

Fecha de recepción: 30-5-2018; aceptación definitiva: 20-6-2018

BIBLD [0213-2052(2018)36;117-134]

RESUMEN: Se presenta un nuevo altar cilíndrico en arenisca con dedicación a la Victoria hallado en la ciudad romana de Los Bañales de Uncastillo (Zaragoza, España). Se plantea una posible ubicación primaria para el monumento en relación con el contexto arqueológico de su hallazgo y con otros de los documentos epigráficos del foro de la ciudad. Además, se propone una datación contextualizando el monumento en el

1. El presente trabajo se integra en las actividades del Plan de Investigación que — por encargo de la Dirección General de Cultura y Patrimonio del Departamento de Educación, Cultura y Deporte del Gobierno de Aragón y la dirección de la Fundación Uncastillo— se viene llevando a cabo en el yacimiento arqueológico romano de Los Bañales (Uncastillo, Zaragoza) (http://www.losbanales.es). 
marco de los altares cilíndricos hispanos, del culto a la Victoria en las provincias hispanas y del papel de esta como uirtus propia de la propaganda altoimperial romana.

Palabras clave: Victoria; culto imperial; auto-representación; propaganda imperial; foros; Flavios.

ABSTRACT: The following papers deals with the presentation of a new cylindric altar dedicated to the Victory attested in the Roman city of Los Bañales de Uncastillo (Zaragoza, Spain). A possible primary position of the monument in relationship within its archaeological context and within other epigraphic evidences of the city is also considered. The paper even proposes a chronology for the monument in connection with the habit of using those cultural cylindric altars in the Spanish provinces and with the cult of Victory and with its presence as one of the virtues of the official imperial propaganda during the High-Empire.

Keywords: Victory; imperial cult; self-representation; official propaganda; forums; Flavians.

Las excavaciones desarrolladas entre 2010 y 2016 en el foro de la ciudad romana de Los Bañales de Uncastillo (Zaragoza) — acaso la Tarraca de Plinio, Ptolomeo y el Cosmógrafo de Ravenna ${ }^{2}$ - nos han obsequiado con un sensacional aparato epigráfico de quince tituli que incluye desde dos ciclos para bases equestres de los comienzos del Principado hasta dos scholae de representación de la elite local adscribibles a las últimas décadas del siglo i d. C. ${ }^{3}$. Entre esos repertorios, sin duda, destaca el que formaría parte de una schola familiar de representación ubicada en el pórtico-occidental del foro de la ciudad y que tuvo en su eje una dedicatoria a la Victoria Aug(usta) o Aug(usti). La erección de esta fue responsabilidad de los notables locales M. Fabius Nouus y Porcia Fauentina ${ }^{4}$.

En el otoño de 2013, tras haberse abordado en ese verano, la excavación de un impresionante nivel de amortización de estatuaria romana en mármol alojado sobre las ruinas de las tabernae meridionales del foro de la

2. ANDREu, J.: "Foederatos Tarracenses: sobre una comunidad de la Tarraconense en los listados de la Naturalis Historia de Plinio el Viejo", Gerión, 35(2), 2017, pp. 103-112.

3. Todo el repertorio, con referencia a las editiones principes respectivas, en ANDREU, J.: "Agentes de la monumentalización urbana en una ciudad del norte de la Citerior: Los Bañales de Uncastillo (Zaragoza, España)", en Bouet, A. (ed.): Monumental! La monumentalisation des villes de l'Aquitanie et de l'Hispanie septentrionale durant le HautEmpire. Bordeaux, 2016, pp. 313-326.

4. JoRDÁn, Á. A., y ANDREU, J.: «Un nuevo conjunto epigráfico en el foro romano de Los Bañales (Uncastillo, Zaragoza)", AEspA, 86, 2014, 243-255. 
ciudad $^{5}$, una violenta tormenta otoñal arrancó de ese mismo nivel la parte superior de una columna de orden toscano de $46,5 \mathrm{~cm}$ de fuste x $38 \mathrm{~cm}$ de diámetro labrada en arenisca y que presentaba un pequeño rehundido en la parte superior, justo en el centro del remate del capitel (Fig. 1). La singular forma del altar se debe a la reutilización de un capitel toscano para su elaboración. De hecho, la tipología del monumento recuerda a algunos capiteles de orden toscano recuperados en el criptopórtico de la basílica del foro de la ciudad, que presenta como peculiaridad más notable el excesivo ábaco en su elaboración ${ }^{6}$. Esa peculiaridad del ábaco permitiría retallarlo fácilmente y convertirlo en el foculus del altar.

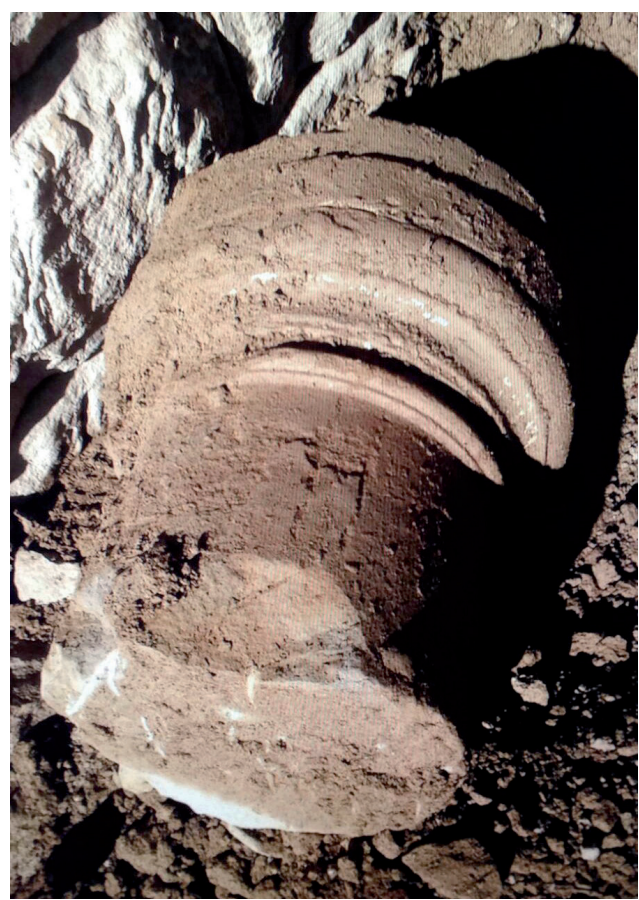

Fig. 1. Altar cilíndrico en el momento de su hallazgo, en el otoño de 2013. (Foto: Joaquín Latorre).

5. Para este y su contenido debe verse Romero, L. y ANDReu, J.: «El programa escultórico del foro de la ciudad romana de Los Bañales: novedades y aspectos iconográficos, programáticos e históricos", en MárQuez, C., y OJEDA, D. (eds.): Escultura romana en Hispania. VIII. Córdoba, 2018, pp. 365-378, 367-375.

6. Romero, L.: "La basílica del foro de Los Bañales (Uncastillo, Zaragoza)", Habis, 48, 2017, pp. 113-131. 
A partir de ahí el ara presenta una estructura con doble franja entrante y saliente, ambas de $6 \mathrm{~cm}$ de altura, sobre el ábaco del capitel. Continúa con un equino de $4 \mathrm{~cm}$, al que sigue un listel plano de $0,5 \mathrm{~cm}$, un caveto de $3 \mathrm{~cm}$, seguido de otro listel plano de $0,5 \mathrm{~cm}$. Después va un collarino de $2 \mathrm{~cm}$ y a continuación el astrágalo de también $2 \mathrm{~cm}$. Posteriormente, posee otro pequeño listel plano de $0,5 \mathrm{~cm}$. Presenta un sumoscapo de fuste liso, labrado en la misma pieza, de $22,50 \mathrm{~cm}$ de altura y $29 \mathrm{~cm}$ de anchura.

Tras su fortuito hallazgo, la pieza fue inmediatamente guardada en la ermita de Nuestra Señora de Los Bañales, que preside el área arqueológica. La reserva de la misma se hizo sin más comprobaciones y considerándola, sencillamente, material arquitectónico del colapso del foro de la ciudad. En mayo de 2018, en el contexto de una reordenación e inventario de parte del material arqueológico allí depositado para su traslado a la nave municipal del Ayuntamiento de Layana — donde hoy se conserva la pieza- se constató que el fuste presentaba una inscripción en caracteres capitales cuadradas $(6 \mathrm{~cm})$ de excelente factura y bisel. Aunque las letras aparecen algo dañadas, especialmente al comienzo y al final de los dos renglones de texto que se han conservado - justo antes de la fractura del soporte por su parte inferior-, de modo inequívoco puede leerse (Figs. 2 y 3$)^{7}$ :

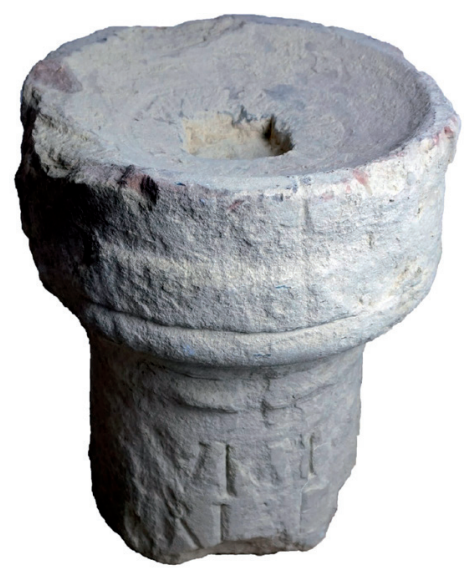

Fig. 2. Altar cilíndrico a la Victoria, con detalle del foculus superior. (Foto: Jorge Torrero).

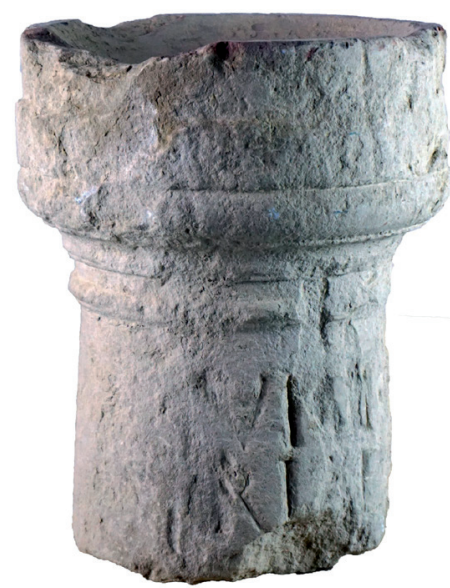

Fig. 3. Altar cilíndrico a la Victoria, vista general. (Foto: Jorge Torrero).

7. El modelo virtual de la inscripción puede verse, gracias al trabajo de Pablo Serrano Basterra, en el Museo Virtual de Los Bañales: https://skfb.ly/6yJAn. 
JAVIER ANDREU PINTADO Y LUIS ROMERO NOVELLA UN ALTAR CILÍNDRICO A LA VICTORIA EN EL FORO DE LOS BAÑALES DE UNCASTILLO (ZARAGOZA, ESPAÑA)

$$
\begin{gathered}
\text { Victo } \\
\text { riae } \\
+
\end{gathered}
$$

En el texto, la 1.3 parece ofrecer el vértice superior de un trazo que podría asemejarse al extremo superior de una A, lo que permitiría una restitución Victo/riae/A[ug], amparada, además, por las razones que más adelante se dirán respecto del que pudo ser el contexto primario del material presentado.

Antes de entrar en la interpretación del monumento, varias consideraciones deben hacerse respecto del soporte empleado, de sus características técnicas y de su vinculación al nivel arqueológico del que fue arrancado por la acción del arrastre de la lluvia en septiembre de 2013.

En primer lugar, nos encontramos ante un altar cilíndrico de carácter cultual, acaso trabajado sobre una antigua columna toscana que habría sido reutilizada y en la que se habría abierto, de forma prominente, un pequeño foculus cuadrangular en su parte superior rebajando esa zona para darle un aspecto ligeramente cóncavo y acorde con esa función de foculus de altar. En segundo lugar, la presencia de este monumento epigráfico en la misma unidad de amortización de material escultórico antes descrita - y que a tenor de los materiales cerámicos que la acompañan, debió formarse antes del siglo III d. C., coincidiendo con la grave crisis que atravesó el municipio, seguramente flavio, que hubo en Los Bañales de Uncastillo ${ }^{8}$ - permite pensar en que el altar que nos ocupa habría sido arrancado de su posición original —como único elemento arquitectónico hallado en el conjunto- en el mismo momento en que se procedió al robo y tesaurización, para fines imprecisos, del aparato escultórico antes anotado y que, acaso, compartía con aquel posición primaria. La coincidencia entre la inscripción dedicada a la Victoria sobre el altar que aquí damos a conocer y la alusión a esa misma en la tabula ansata central de la ya citada schola de representación de los Fabii y las Porciae - con paleografía, además, absolutamente idéntica en tipo y dimensiones (Fig. 4) - permite pensar en que el material escultórico recuperado en el nivel de amortización de estatuaria que describimos formaría parte del programa iconográfico y decorativo de ese recinto de exaltación dinástica de la elite local del municipio de Los Bañales y en el que figuraron

8. Andreu, J. y Delage, I.: "Diuturna atque aeterna ciuitas?: sobre la sostenibilidad de los municipia Latina hispanorromanos a partir de un caso paradigmático: Los Bañales de Uncastillo", en ANDReu, J. (ed.): Oppida labentia. Transformaciones, cambios y alteración en las ciudades hispanorromanas entre el siglo II y la tardoantigüedad. Uncastillo, 2017, pp. 345-374, 359-363. 


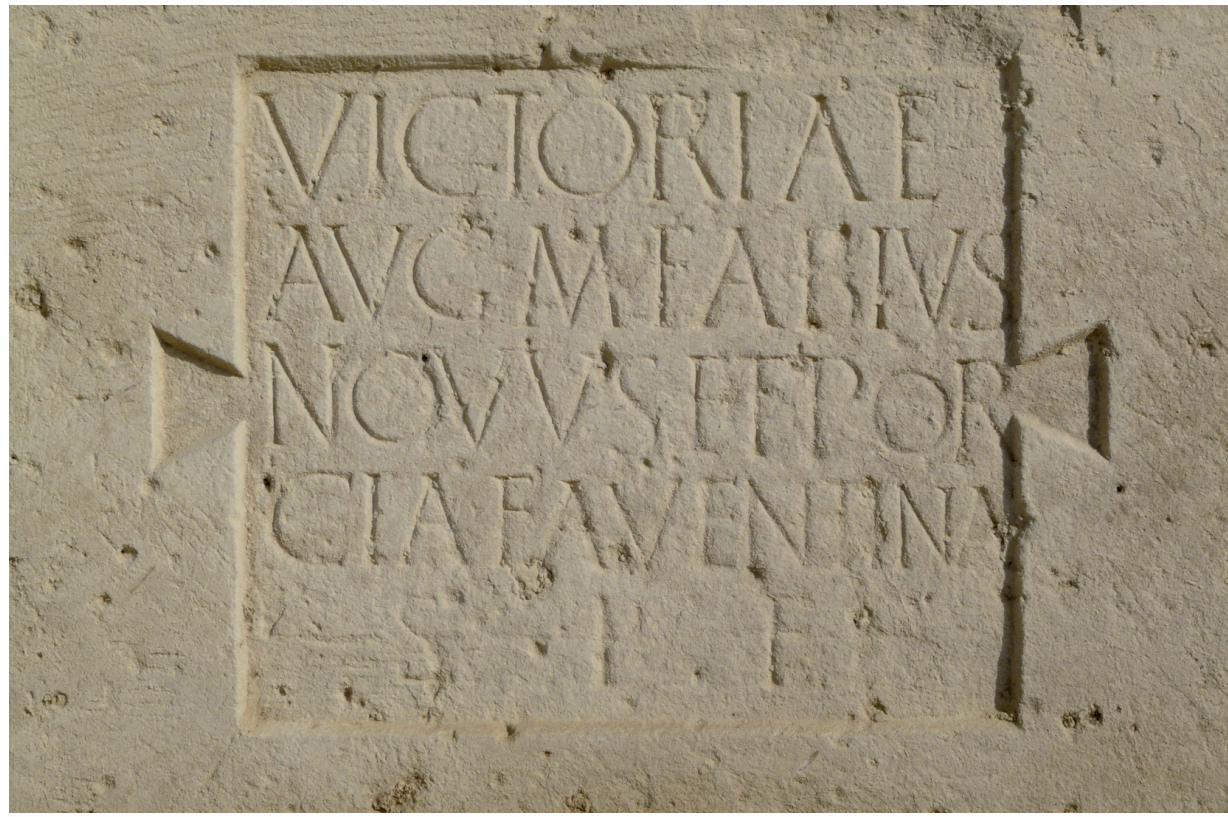

Fig. 4. Inscripción central, en tabula ansata, dedicada a la Victoria por M. Fabius Nouus y Porcia Fauentina. (Foto: Jorge Torrero).

asimismo estatuas de M. Fabius Nouus, Porcia Fauentina, Porcia Germulla y L. Fabius Placidus. La presencia entre ese material escultórico recuperado de restos de estatuas tanto masculinas como femeninas así lo aconseja al tiempo que el hallazgo en ese mismo nivel de un sensacional thoracatus de Domiciano, fragmentado pero restituible? , permite alimentar la hipótesis de que, verosímilmente ${ }^{10}$, esa representación de Domiciano con porte militar fuera la central de esta schola. Esta, más allá de su función de representación, podemos asegurar ahora que tuvo un carácter cultual una vez que en ella pudo obrar el altar cilíndrico que aquí presentamos, acaso

9. Romero, L., Andreu, J., y Gabaldón, M.: «Un thoracatus imperial en Los Bañales (Uncastillo, Zaragoza)", Zephyrus: revista de Prehistoria y Arqueologia, 73, 2014, pp. 197216, con propuesta de restitución en Maqueda, R., Luque, M., Andreu, J. y Romero, L.: "Princeps resurgens: archaeological research and photogrammetric documentation in the study of a Roman thoracata statue of Los Bañales (Uncastillo, Zaragoza)", Virtual Archaeology Review, 6-13, 2015, pp. 65-71.

10. Romero, L. y Andreu, J.: op. cit., p. 368. 
JAVIER ANDREU PINTADO Y LUIS ROMERO NOVELLA UN ALTAR CILÍNDRICO A LA VICTORIA EN EL FORO DE LOS BAÑALES DE UNCASTILLO (ZARAGOZA, ESPAÑA)

colocado frente a la estatua principal, y axial, del recinto ${ }^{11}$. La iconografía de esa escultura puede aportar algunos datos contextuales interpretativos que, nos parece, guardan relación clara con el texto del nuevo documento epigráfico y con la filosofía del propio monumento, como más adelante veremos.

Consideración especial merece el soporte, absolutamente inusual en el norte de la Tarraconense a no ser por un ejemplar dedicado a las Matres Apellares procedente de Badarán, en La Rioja $(A E$ 1999, $924=$ Tabla 1) que parece también realizado sobre una columna de orden toscano aunque en una fecha bastante posterior - del siglo III d. C. ${ }^{12}$ - a la que, altoimperial —aunque solo sea a juzgar por los argumentos paleográficos-, proponemos para nuestro nuevo ejemplar. El catálogo de altares cilíndricos de Hispania, tanto si se tienen en cuenta los ejemplares confirmados (Tabla 1) como si se valoran los dudosos (Tabla 2) y aun los anepígrafos (Tabla 3), dibuja una geografía de dispersión con un claro predominio en la Bética — con ejemplares en Iulipa $\left(C I L \mathrm{II}^{2} / 7\right.$, 938), Vrgapa (CIL II ${ }^{2} / 5$, 911), Corduba (CIL II $/ 7$, 253 y 725), Ilipula Minor (CIL II ${ }^{2} / 5,895$ ) o el, posteriormente reconvertido en puteal, de Trigueros, acaso traído de Asido (CILA 1, 70) ${ }^{13}$ — , en el centro de Lusitania — con ejemplares cerca de Aeminium (ILER 930) y un buen conjunto de altares anepígrafos procedentes de Augusta Emerita (Tabla 3) - , y en dos focos periféricos de la Hispania Citerior, el de Carthago Noua (HEp5, 588 y una riquísima concentración de ejemplares anepígrafos, principalmente basas neoáticas, en el teatro [Tabla 3]), y el de Bracara Augusta con ejemplares con inscripción de cronología altoimperial (HEp15, 476 e ILER 1028). El altar que nos ocupa, de Los Bañales de Uncastillo, constituiría, a día de hoy, el más septentrional de los hallados en Hispania junto con el citado de Badarán, acaso adscribible al territorium de la antigua Vareia (Logroño). No es la primera vez que el foro de Los Bañales de Uncastillo nos obsequia con rasgos de hábito epigráfico ciertamente inusuales para

11. Para la relación entrGe estos monumentos y el carácter cultual de sus contextos primarios véase Carvalho, H., Encarnação, J. d', Martins, M. y Cunha, A.: "Altar romano encontrado em Braga", Forum, 40, 2006, pp. 31-41, 35. Sobre el destino de la estatua tras la damnatio memoriae de Domiciano pueden verse las consideraciones hechas en ROMERo, L., Andreu, J. y Gabaldón, M.: op. cit., p. 209.

12. Castillo, M. ${ }^{a}$ J.: "Una dedicatoria a las Matres en Badarán (La Rioja)", HAnt., 23, 1999, pp. 137-141.

13. Para este, véase Beltrán Fortes, J. y Stylow, A. U.: «Un aspecto del culto imperial en el suroeste bético: el "puteal" de Trigueros (Huelva), un altar dedicado a Augusto", en Nogales, T. y GonzÁlez, J. (eds.): Culto imperial: política y poder. Roma, 2007, 239-250. 
la latitud en que obró la ciudad ${ }^{14}$ lo que, sin duda, subraya la notable entrada de los influjos oficiales a esta ciuitas del interior del distrito de la colonia Caesar Augusta y nos obliga a reflexionar sobre el posible carácter propagandístico de la misma, a medio camino entre dos ciudades de idéntico carácter, Caesar Augusta, fundada por Augusto en 15/14 a. C., y Pompelo, fundada por Pompeyo en el invierno de 74 a. C. ${ }^{15}$.

Tabla 1: Altares cilíndricos en Hispania: ejemplares seguros

\begin{tabular}{|c|c|c|c|c|}
\hline REFERENCIA & PROCEDENCIA & TeÓnimo & PROMOTOR & CRONOLOGÍA \\
\hline CIL II ${ }^{2} / 7,196$ & Sacili & $\begin{array}{c}\text { Gen(io) } \\
\text { m(unicipum) }\end{array}$ & $\begin{array}{c}m \text { (unicipium) } \\
M(\text { artiale })\end{array}$ & Desconocida \\
\hline CIL II, 951 & Ilipula & Aug(usto) & $\begin{array}{l}\text { Sempronia } \\
\text { Anull[ina] }\end{array}$ & Augústea \\
\hline CIL II ${ }^{2} / 7,938$ & Iulipa & $\begin{array}{l}\text { Laribus } \\
\text { Aug(ustis) }\end{array}$ & $\begin{array}{c}\text { L(ucius) Cornelius } \\
\text { Firmillus } \\
\text { Augustalis } \\
\end{array}$ & $\begin{array}{l}\text { Mediados del } \\
\text { s. II d. C. }\end{array}$ \\
\hline CILA 1, 70 & Trigueros & $\begin{array}{c}\text { donum } \\
\text { Aug(usto) }\end{array}$ & $\begin{array}{c}\text { C. Sempronius } \\
\text { Proculus } \\
\text { Seruilianus } \\
\text { C. Sempronius } \\
\text { Seruilianus } \\
\end{array}$ & Augústea \\
\hline HEр9, 483 & Badarán & $\begin{array}{l}\text { Matribus } \\
\text { Apellares }\end{array}$ & $\begin{array}{c}\text { (A)emilius Quil } \\
\text { ntilianus }\end{array}$ & s. III d. C. \\
\hline HEp 15, 476 & $\begin{array}{l}\text { Bracara } \\
\text { Augusta }\end{array}$ & sacrum & Desconocido & $\begin{array}{l}\text { Comienzos del } \\
\text { s. I d. C. }\end{array}$ \\
\hline ILER 1028 & $\begin{array}{l}\text { Bracara } \\
\text { Augusta }\end{array}$ & $\begin{array}{c}\text { Aug(usto) } \\
\text { pont (ifici) } \\
\text { max (imo) } \\
\text { trib(unicia) } \\
\text { pot(estate) XXI } \\
\text { sacrum } \\
\end{array}$ & $\begin{array}{l}\text { Paullus Fabius } \\
\text { Maxsimus }\end{array}$ & Augústea \\
\hline HEp 5, 588 & $\begin{array}{l}\text { Carthago } \\
\text { Noua }\end{array}$ & Salr]api & $\begin{array}{c}M(\text { arcus }) \text { Brosius } \\
M \text { (arci) f(ilius) }\end{array}$ & Augústea \\
\hline ILER 930 & Aeminium & Tabudico & $\begin{array}{c}\text { C(aius) Fabius } \\
\text { Viator }\end{array}$ & s. I d. C. \\
\hline
\end{tabular}

14. AndReu, J.: "Una nueva inscripción romana con numeral procedente de la Tarraconense (Los Bañales de Uncastillo, Zaragoza)", Epigraphica 80, 2018, 201-208.

15. Al respecto puede verse Andreu, J., Romero, L. y Montoya, R.: "Los Bañales (Uncastillo, Zaragoza): ciuitas augústea", Anales de Arqueología Cordobesa, 25-26, $2014-$ 2015, 49-70. 
JAVIER ANDREU PINTADO Y LUIS ROMERO NOVELLA

UN ALTAR CILÍNDRICO A LA VICTORIA EN EL FORO DE LOS BAÑALES

DE UNCASTILLO (ZARAGOZA, ESPAÑA)

Tabla 2: Altares cilíndricos en Hispania: ejemplares dudosos

\begin{tabular}{|c|c|c|c|c|c|}
\hline REFERENCIA & Procedencia & TEÓNImo & PROMOTOR & CRONOlOGÍA & $\begin{array}{c}\text { PUBLICACIÓN } \\
\text { COMO }\end{array}$ \\
\hline CIL $\mathrm{II}^{2} / 5,911$ & Vrgapa & $\begin{array}{l}\text { Herculem } \\
\text { Primigenium } \\
\text { Aug(usto) } \\
\text { sacrum }\end{array}$ & $\begin{array}{c}\text { Ciniluls } \\
\text { C(aii)f(ilius) }\end{array}$ & s. I d. C. & Pedestal \\
\hline CIL II ${ }^{2} / 7,253$ & Corduba & $\begin{array}{l}\text { Augusto } \\
\text { sacrum }\end{array}$ & Desconocido & Augusto & $\begin{array}{c}\text { Columna o } \\
\text { altar }\end{array}$ \\
\hline CIL II ${ }^{2} / 7,725$ & Corduba & $\begin{array}{c}\text { Veneri } \\
\text { Augustae }\end{array}$ & $\begin{array}{l}\text { L. Aelius } \\
\text { Aelianus }\end{array}$ & $\begin{array}{c}2^{\text {a }} 1 / 2 \\
\text { siglo II }\end{array}$ & $\begin{array}{c}\text { Base de } \\
\text { estatua }\end{array}$ \\
\hline CIL II ${ }^{2} / 5,895$ & $\begin{array}{l}\text { Ilipula } \\
\text { Minor }\end{array}$ & $\begin{array}{l}\text { [Minelruae } \\
\text { Aug(ustae) } \\
\text { s(acrum) }\end{array}$ & $\begin{array}{l}\text { [---Inius } \\
\text { Quir(ina) } \\
\text { Optatus }\end{array}$ & $\begin{array}{l}2^{\text {a } 1 / 2} \\
\text { siglo II }\end{array}$ & Pedestal \\
\hline
\end{tabular}

Además de la originalidad que supone el monumento en el contexto de las manifestaciones del hábito epigráfico en la Tarraconense, su aspecto formal no guarda relación alguna con los tipos monumentales que fueran recopilados al efecto por $G$. Gamer ${ }^{16}$ ni con los tipos de altares circulares atestiguados en las provincias hispanas ${ }^{17}$. Ello es debido, principalmente, a haberse generado a partir de la reutilización de un capitel toscano anterior. Este tipo de trabajos reutilizando material arquitectónico para la construcción de altares circulares, si bien no es muy común, presenta un paralelo en Hispania en el caso del ya citado altar de Badarán (La Rioja), ya del siglo III d. C.

16. GAMER, G.: Formen römischer Altäre auf der Hispanischen Halbinsel. Mainz, 1989, pp. 124-168.

17. Gamer, G.: op. cit., pp. 126-128 y Beltrán Fortes, J.: Las arae de la Baetica. Málaga, 1988, p. 22. 
JAVIER ANDREU PINTADO Y LUIS ROMERO NOVELLA

UN ALTAR CILÍNDRICO A LA VICTORIA EN EL FORO DE LOS BAÑALES DE UNCASTILLO (ZARAGOZA, ESPAÑA)

Tabla 3: Altares cilíndricos anepígrafos en Hispania

\begin{tabular}{|c|c|c|c|}
\hline PROCEDENCIA & UBICACIÓN & CRONOLOGÍA & BIBLIOGRAFÍA $^{18}$ \\
\hline Baelo Claudia & $\begin{array}{l}\text { Templo A del } \\
\text { foro }\end{array}$ & Desconocida & $\begin{array}{l}\text { Nicolini, G., Domergue, C., Nony, D. } \\
\text { y García-Bellido, A.: 1968, 394-396; } \\
\text { García y Bellido, A.: 1968, 394-396 y } \\
\text { Beltrán Fortes, J.: 1988, 131, no } 19 .\end{array}$ \\
\hline Canama & Desconocida & Flavia & $\begin{array}{l}\text { BELTRÁN FoRTES, J.: 1998, 140, no } 136 \text { y } \\
\text { GAMER, G.: } 1989,265, \mathrm{n}^{\circ} \text { SE } 32 .\end{array}$ \\
\hline Corduba & Desconocida & Antoniana & Beltrán Fortes, J.: 1998, 140, nº 60. \\
\hline Italica & Teatro & Tardoaugústea & $\begin{array}{l}\text { LuZÓN, J. M. }{ }^{a}: 1978,277-281 \text { y FuCHS, } \\
\text { M.: 1987, 143-144. }\end{array}$ \\
\hline Italica & Teatro & Tardoaugústea & $\begin{array}{l}\text { LUZÓN, J. M. }{ }^{a}: 1978,281-286 \text { y FuCHs, } \\
\text { M.: } 1987,143-144 .\end{array}$ \\
\hline Italica & Teatro & Tardoaugústea & $\begin{array}{l}\text { LuZÓN, J. M. }{ }^{\text {a }} \text { 1978, 286-289 y FuCHs, } \\
\text { M.: 1987, 143-144. }\end{array}$ \\
\hline Malaca & Teatro & Julio-claudia & $\begin{array}{l}\text { Rodríguez Oliva, P.: 1976, 77-80 y } \\
\text { Beltrán Fortes, J.: 1988, 139, nº } 114 .\end{array}$ \\
\hline Carthago Noua & Desconocida & Desconocida & GAMER, G.: 1989, 246, nº MU 5. \\
\hline Carthago Noua & Teatro & Augústea & $\begin{array}{l}\text { RAMALLO, S. F.: 1999(a), 526-534 y } \\
\text { 1999(b), 53-69. }\end{array}$ \\
\hline Carthago Noua & Teatro & Augústea & $\begin{array}{l}\text { RAMALLO, S. F.: 1999(a), 534-537 y } \\
\text { 1999(b), 70-79. }\end{array}$ \\
\hline Carthago Noua & Teatro & Augústea & $\begin{array}{l}\text { RAMALlo, S. F.: 1999(a), 537-542 y } \\
\text { 1999(b), 80-89. }\end{array}$ \\
\hline $\begin{array}{l}\text { Augusta } \\
\text { Emerita }\end{array}$ & Desconocida & $\begin{array}{l}\text { Julio-claudia/ } \\
\text { flavia }\end{array}$ & $\begin{array}{l}\text { GarCía y Bellido, A.: 1949, 412-413, } \\
\mathrm{n}^{\circ} 413 \text { y GAMER, G.: 1989, 197, n BA } \\
60 .\end{array}$ \\
\hline $\begin{array}{l}\text { Augusta } \\
\text { Emerita }\end{array}$ & Desconocida & $\begin{array}{l}\text { Julio-claudia/ } \\
\text { flavia }\end{array}$ & $\begin{array}{l}\text { García y Bellido, A.: 1949, 412-413, } \\
\text { no } 413 \text { y GaMer, G.: 1989, 197, nº BA } \\
61 .\end{array}$ \\
\hline
\end{tabular}

18. 1. La bibliografía de la tabla, por orden de cita: Nicolini, G., Domergue, C., Nony, D. y García-Bellido, A.: "Les fouilles de la Casa de Velázquez à Belo-Bolonia (Cádiz) en 1967 (Variété)", MCV, 4, 1968, pp. 393-40; García y BelLido, A.: Esculturas romanas de España y Portugal. Madrid, 1949; Beltrán Fortes, J.: op. cit.; Gamer, G.: op. cit.; Luzón, J. M. ${ }^{a}$ : "Die neuattischen Rund-Aren von Italica", MM, 19, 1978, pp. 272-289; Fuchs, M.: Untersuchungen zur Ausstattung römischer Theater in Italien und den Westprovinzen des Imperium Romanum. Mainz, 1987; Rodríguez Oliva, P.: "Un ara romana de Málaga", Jábega, 5, 1976, 77-80; Ramallo, S. F.: "Drei neuattische Rundaltäre aus dem Theater von Cartago Noua (Cartagena, Spanien)", Archäologische Anzeiger 4, 1999(a), pp. 523-542 y El programa ornamental del teatro romano de Cartagena. Madrid, 1999(b); Nogales, T.: "La escultura", en Dupré, X. (ed.): Las capitales provinciales de Hispania. 2. Mérida. Colonia Augusta Emerita. Roma, 2004, pp. 113-129. 
JAVIER ANDREU PINTADO Y LUIS ROMERO NOVELLA

UN ALTAR CILÍNDRICO A LA VICTORIA EN EL FORO DE LOS BAÑALES

DE UNCASTILLO (ZARAGOZA, ESPAÑA)

\begin{tabular}{|c|c|c|c|}
\hline $\begin{array}{l}\text { Augusta } \\
\text { Emerita }\end{array}$ & Desconocida & $\begin{array}{l}\text { Julio-claudia/ } \\
\text { flavia }\end{array}$ & $\begin{array}{l}\text { GaRCía y Bellido, A.: 1949, 412-413, } \\
\text { n}^{\circ} 413 \text { y GAMER, G.: 1989, 197, nº BA } \\
62 .\end{array}$ \\
\hline $\begin{array}{l}\text { Augusta } \\
\text { Emerita }\end{array}$ & Columbarios & Desconocida & GaMer, G.: 1989, 197, nº BA 59. \\
\hline $\begin{array}{l}\text { Augusta } \\
\text { Emerita }\end{array}$ & Teatro & s. II d. C. & $\begin{array}{l}\text { García y Bellido, A.: } 1949,410, \mathrm{n}^{\circ} \\
410 \text { y Nogales, T.: } 2004,117 .\end{array}$ \\
\hline
\end{tabular}

Cuando se realizó la editio princeps de la schola de representación dedicada a la Victoria imperial por M. Fabius Nouus y Porcia Fauentina en el foro de Los Bañales de Uncastillo - más que probable contexto primario del altarcito que nos ocupa- se planteó, en virtud de la paleografía, una datación julio-claudia aunque dejando esta abierta ${ }^{19}$. Más adelante, y poniéndola en relación con los hábitos de auto-representación propios de ciues de nueva promoción, se vinculó el monumento a la época flavia ${ }^{20}$. Recientemente se ha fechado también así en una obra de conjunto ajena a los primeros editores del material de referencia y esa datación parecen también aconsejarla los últimos estudios sobre la evolución arquitectónica del foro de Los Bañales ${ }^{21}$.

Como es sabido, las dedicaciones a la Victoria en las provincias hispanas - $-\mathrm{y}$ en particular las vinculables al ámbito imperial — se reparten, fundamentalmente, a partir de la época flavia ${ }^{22}$, patrón este que es coincidente con el que exhiben esas mismas dedicaciones en el ámbito general del Occidente Latino ${ }^{23}$. Aunque el culto a la Victoria alcanzase notable popularidad bajo el Principado de Augusto, la vinculación de esta a un individuo concreto - y no solo a una abstracción del tipo uirtus - y la construcción de la fórmula Victoria + genitivo, comenzó a desarrollarse de modo muy notable a partir de la guerra civil de 68-69 d. C. en que tanto Otón como Galba y Vitelio y, finalmente, Vespasiano, la emplearon en su

19. Jordán, Á. A. y Andreu, J.: op. cit., p. 252.

20. ANDREU, J.: op. cit., p. 320.

21. Navarro, M.: Perfectissima femina. Femmes de l'élite dans l'Hispanie Romaine. Bordeaux, 2017, p. 765 y Romero, L.: "The roman forum of Los Bañales (Uncastillo, Zaragoza): Building, remodelling and reutilisation of a forum from the conuentus Caesaraugustanus", en 19th International Congress of Classical Archaeology (Bonn, 2018), en prensa, s. pp.

22. Perea, S.: "El culto a la Victoria Augusta en Roma y en la Hispania altoimperial", en Hernández Guerra, L. (ed.): El mundo religioso hispano bajo el Imperio Romano. Pervivencias y cambios. Valladolid, 2007, pp. 221-235, 232.

23. NoREÑA, C.: Imperial Ideals in the Roman West. Representation, circulation, power. Cambridge, 2011, p. 165, Figs. 3, 4. 
propaganda conociendo un gran auge a partir de este Princeps ${ }^{24}$ tanto en la iconografía estatuaria y en el lenguaje epigráfico como en el ámbito monetal ${ }^{25}$ y en el religioso. Al menos desde $69 \mathrm{~d}$. C. la Victoria aparece citada en el juramento de los fratres Aruale $^{26} \mathrm{y}$ es desde ese momento en que la leyenda VICTORIA AVG se generaliza en la numismática romana ${ }^{27}$. Sabemos, además, que Vespasiano restauró el aedes Victoriae en Roma (ILS 3813). Para entonces, y de modo especial a partir de Domiciano, esta alusión resultó notablemente recurrente prolongándose su uso hasta entrado el siglo II d. C. y teniendo una gran presencia en las monedas, medio que actuó de forma nítida como aliado para la expansión de determinados ideales políticos emanados de la propaganda oficial ${ }^{28}$. Mucho tuvo que ver en ello el último emperador citado, cuyos triunfos sobre los Chatos, los Marcomanos y los Dacios entre el 83 y el 89 d. C., fueron celebrados, iconográfica y visualmente, vinculados a la idea de la Victoria ${ }^{29}$ en un claro intento del último de los flavios por redefinir esta $u i r t u s^{30}$.

Con Vespasiano la alusión a la Victoria, y, en concreto, a la Victoria Augusti, resulta programática en las primeras acuñaciones de este emperador por más que esta, en diversas actitudes — portando escudo (RIC 1195), con corona de laurel (RIC 1431), colocando escudo sobre un trofeo (RIC 1068), o sobre proa de barco bajo la leyenda VICTORIA NAVALIS (RIC 336) - fuese recurrente en la Historia de su amonedación. Así, en 71 d. C. ya encontramos la leyenda VICTORIA AVGVSTI con representación de la Victoria con escudo y palma (RIC 355) al igual que en ese mismo año esa leyenda aparece asociada al tipo de la Victoria sobre globo terrestre (RIC 47) perdurando después ese rótulo, con tipos variados, desde 73 d. C.

24. Gagé, J.: "Un thème de l'art impèrial romain: la Victoire d'Auguste", MEFRA, 49, 1932, pp. 61-92, 64; FEARS, J. R.: "The theology of Victory in Rome: approaches and problems", $A N R W$ 2, 17.2, 1981, pp. 736-826, 812-814 y NoreÑA, C.: op. cit., pp. 293-294.

25. Véase, al respecto Beluinger, A. R. y Alkins, M.: Victory as a coin type. New York, 1964, pp. 57-62. p. 127.

26. Paladino, I.: Fratres Aruales. Storia di un collegio sacerdotale romano. Roma, 1988,

27. HÖLscher, T.: Victoria Romana. Archäologische Untersuchungen zur Geschichte und Wesensart der römischen Siegesgöttin von den Anfängen bis zu Ende des 3. Jhs. n. Chr. Mainz, 1967, pp. 18-19.

28. ANDO, C.: Imperial Ideology and Provincial Loyalty in the Roman Empire. Berkeley 2000, pp. 278-293. Para el tema bajo los Flavios, véase Suess, J.: Divine Justification: Flavian Imperial Cult. Oxford, 2011, pp. 77 y 85.

29. GERGEL, R. A.: "An allegory of Imperial Victory on a cuirassed statue of Domitian", Record of the Art Museum. Princeton University, 45-1, 1986, pp. 2-15, 10.

30. Tuck, S. L.: "The origins of Imperial Hunting Imagery: Domitian and the Redefinition of Virtus under the Principate", Greece \& Rome, 52-2, 2005, pp. 221-245. 
JAVIER ANDREU PINTADO Y LUIS ROMERO NOVELLA UN ALTAR CILÍNDRICO A LA VICTORIA EN EL FORO DE LOS BAÑALES DE UNCASTILLO (ZARAGOZA, ESPAÑA)

(RIC 362) - año en que también consta alguna acuñación con la efigie de Domiciano en el anverso y esta misma referencia (RIC 560) - hasta finales de su gobierno (RIC 221). Precisamente bajo su mandato, esa misma leyenda aparece en reversos acuñados, entre 70 y 81 d. C., con Domiciano como César (RIC 1056 y 677), ganando más popularidad después, ya con Domiciano en el trono, la fórmula IOVI VICTORI o el simple uso de la Victoria - escribiendo en un escudo el rótulo DE GERMANIS o sentada sobre escudos germanos- en piezas acuñadas hacia 86 d. C. (RIC 476 y $R P C$ II, 2521 respectivamente), estas últimas en clara relación con las campañas germánicas viéndose aquella reemplazada, después, por Marte y por Minerva ${ }^{31}$. Estos tipos y su paralelo iconográfico con algunos de los motivos decorativos de la coraza de la estatua domiciánea que, a nuestro juicio - ahora con más argumentos dada la clara conexión estratigráfica entre el altar que nos ocupa y los restos escultóricos a los que pertenece aquella- presidiría el recinto en que, muy probablemente, obró nuestro altar cilíndrico (Fig. 5) fueron utilizados hace algunos años para proponer que la erección de la estatua de Domiciano en actitud militar habría sido inspirada por la extraordinaria popularidad de la victoria de este sobre los Germanos ${ }^{32}$ que, acaso, habría generado en el Imperio un impacto del mismo calibre que el que, algunos años antes había generado la victoria de Claudio en Britannia ${ }^{33}$.

Sea como fuere, lo que parece claro es que este nuevo documento permite concluir que el recinto en que este obró - seguramente el promovido de forma liberalis por M. Fabius Nouus y Porcia Fauentina- fue un recinto de culto, vinculado al culto al emperador, acaso jugando con la habitual ambigüedad — recomendada, incluso, por los propios antiguos ${ }^{34}$ de la fórmula Victoria Aug(usta) o Victoria Aug(usti) ${ }^{35}$. Muy verosímilmente, a juzgar por los datos aquí apuntados, el recinto debió ser erigido en época flavia en un acto de evergetismo cívico que no solo buscó vincular el prestigio de las familias promotoras — la Porcia y la Fabia- a la imagen imperial sino, también, obsequiar al foro de Los Bañales de

31. Morawiecki, L.: "The symbolism of Minerva on the coins of Domitian", Klío, 59, 1-2, 1977, pp. 185-194.

32. Romero, L., Andreu, J., y Gabaldón, M.: op. cit., p. 209.

33. Standing, G.: "The Claudian Invasion of Britain and the Cult of the Victoria Britannica", Britannia, 34, 2003, pp. 281-288 y SCHERF, J.: "Victoria", en Der Neue Pauly. Enzyklopädie der Antike. Band 12/2. Stuttgart-Weimar, 2002, p. 190, además de T. HÖLSCHER, op. cit., p. 176.

34. Gell. NA. 10, 1, 7-9.

35. Fishwick, D.: "The Imperial Cult in Roman Britain", Phoenix, 15-4, 1961, pp. 213229. 

DE UNCASTILLO (ZARAGOZA, ESPAÑA)

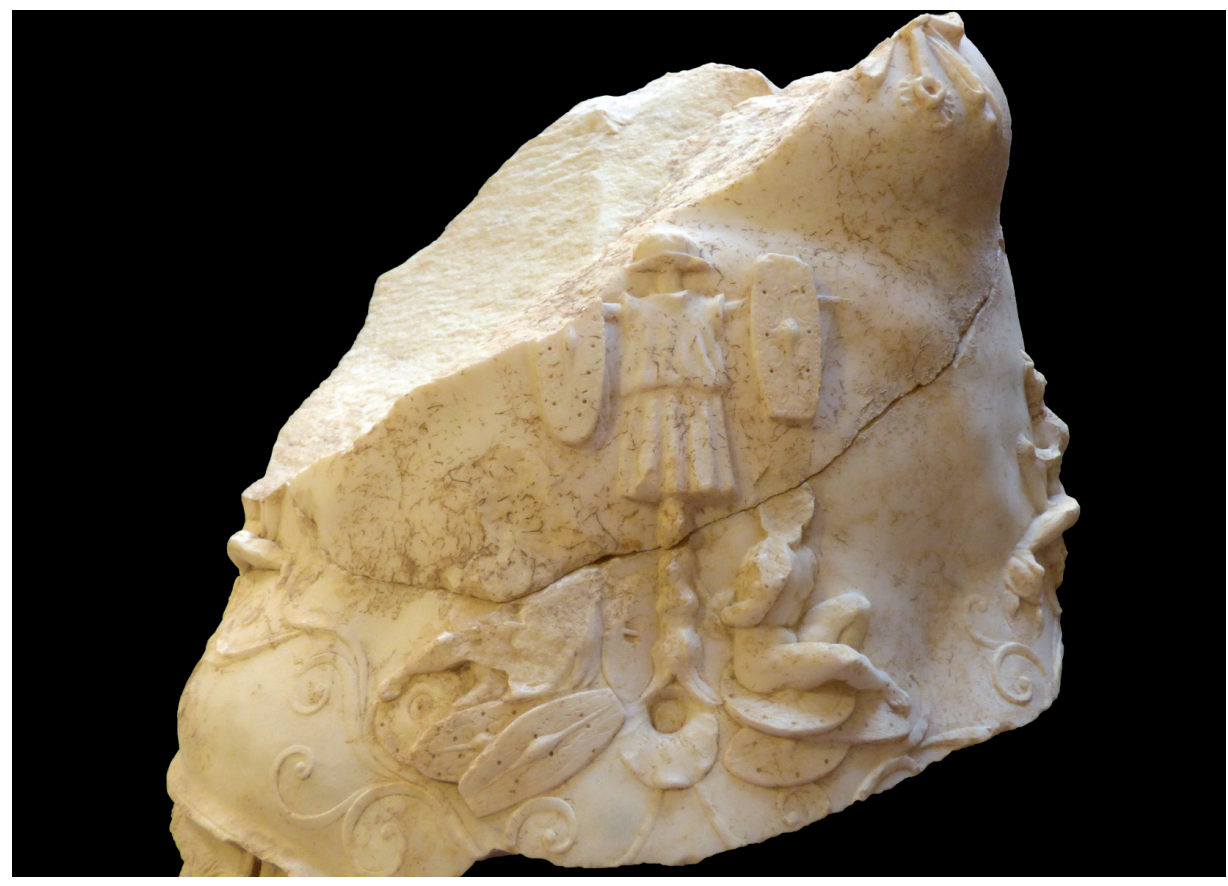

Fig. 5. Coraza de la estatua thoracata de Domiciano recuperada en Los Bañales en el mismo nivel arqueológico que el altar cilíndrico. (Foto: Jorge Torrero).

Uncastillo con un sacellum de culto del que, hasta donde sabemos, carecía hasta la fecha. Este se colocó, además, abierto al pórtico occidental y en una clara posición axial respecto de la plaza forense aspecto este que contribuiría a resaltar la importancia programática del conjunto en el marco de la arquitectura de la plaza.

Más difícil de resolver - $\mathrm{y}$ como suele suceder en este tipo de $\operatorname{casos}^{36}$ - es si, tras esa alusión a la Victoria, tanto en el nuevo altar como en la placa central del podium del recinto, hubo sencillamente un intento de difundir un valor que, como se ha visto por los datos numismáticos, se percibía como esencial en la propaganda imperial oficial — valor el de la Victoria reconocido como útil en este sentido desde los tiempos de Cicerón ${ }^{37}$ - un deseo de asimilar este a la promoción de la ciudad al estatuto de municipio de derecho Latino que se habría operado en esas

36. Beltrán Fortes, J.: “Un monumento romano dedicado a la Victoria en el Museo de Antequera", Mainake, 4-5, 1983, pp. 227-236.

37. Cic. Nat. D. 2, 61. 
JAVIER ANDREU PINTADO Y LUIS ROMERO NOVELLA

UN ALTAR CILÍNDRICO A LA VICTORIA EN EL FORO DE LOS BAÑALES

DE UNCASTILLO (ZARAGOZA, ESPAÑA)

mismas décadas - manifestando de ese modo, los acaso nuevos ciues del lugar, su lealtad a la dinastía causante de dicha promoción - o bien el afán de celebrar públicamente una victoria militar imperial —verosímilmente la de Domiciano sobre los Chatos para la que las fuentes subrayan, incluso, la recurrente exageración de su triumphus ${ }^{38}$ debido en parte al interés de este emperador por legitimarse con una victoria externa a la dinástica del Bellum Iudaicum ${ }^{39}$ - en la que convergieran, además, las otras dos razones aquí aducidas ${ }^{40}$.

\section{BIBLIOGRAFÍA}

ANDO, C.: Imperial Ideology and Provincial Loyalty in the Roman Empire. Berkeley, 2000.

ANDREU, J.: "Agentes de la monumentalización urbana en una ciudad del norte de la Citerior: Los Bañales de Uncastillo (Zaragoza, España)", en Bouet, A. (ed.): Monumental! La monumentalisation des villes de l'Aquitanie et de l'Hispanie septentrionale durant le Haut-Empire. Bordeaux, 2016, pp. 313-326.

38. Tac. Ger. 37,5 y, en ese sentido, también, Suet. Dom. 13. Sobre esta campaña y su repercusión propagandística véase GalimberRI, A.: "The Emperor Domitian", en Zissos, A. (ed.): A Companion to the Flavian age of Imperial Rome. Chichester, 2016, pp. 97-99 y, antes, Darwall-Smith, R.: Emperors and Architecture: A Study of Flavian Rome. Bruxelles, 1996, 254.

39. Tuck, S. L. "Imperial Image-Making", en Zissos, A. (ed.): op. cit., pp. 111-112.

40. Llama la atención que un municipio del interior de la Tarraconense celebrase una victoria imperial acaecida en tierras germanas y, por tanto, sin aparente conexión con la historia municipal. Dadas las conexiones que la figura de Q. Sempronius Vitulus, promotor de un ciclo estatuario en honor del emperador Tiberio en el foro de la ciudad (ANDreu, J.: op. cit.) tuvo con el exercitus Hispanicus de época de Augusto (Ventura, Á., ANDReu, J. y Romero, L.: "Equites del ala Tauriana al servicio de Roma: los Sempronii del oppidum de Los Bañales (Hispania citerior)", Gladius, 38, 2018, pp. 35-45) y la conexión histórica entre la ciudad y, al menos, la legio IV Macedonica (ANDreu, J., ROMero, L., y Montoya, R.: op. cit., pp. 52-58) resulta sugerente que, teniendo en cuenta que en la campaña contra los Chatos parece participó la legio IX Hispana — que convivió con las legiones $I V$ Macedonica, VI Victrix y X Gemina en el frente cántabro al menos hasta el 19 a. C. (sobre esta veáse, al menos, KeppIE, L.: "Legiones II Augusta, VI Victrix, IX Hispana, XX Valeria Victrix", en Le Bohec, Y. y Wolff, C. (eds.): Les Légions de Rome sous le Haut-Empire. Tome I. Lyon, 2000, pp. 25-37, con bibliografía y fuentes) - la presencia en el ordo decurionum del municipio flavio de Los Bañales de individuos descendientes de veteranos de alguna de esas legiones $-\mathrm{y}$, por tanto, con conexiones con la $I X-$ viera con buenos ojos la celebración de dicha victoria que, en cualquier caso, cuadraba cn el contexto de promoción municipal de la ciudad vinculado y debido a la dinastía flavia. 
ANDREU, J.: "Foederatos Tarracenses: sobre una comunidad de la Tarraconense en los listados de la Naturalis Historia de Plinio el Viejo", Gerión, 35(2), 2017, pp. 103-112.

ANDREU, J.: "Una nueva inscripción romana con numeral procedente de la

Tarraconense (Los Bañales de Uncastillo, Zaragoza)", Epigraphica, 80, 2018, pp. 201-208.

Andreu, J. y Delage, I.: "Diuturna atque aeterna ciuitas?: sobre la sostenibilidad de los municipia Latina hispanorromanos a partir de un caso paradigmático: Los Bañales de Uncastillo", en ANDreU, J. (ed.): Oppida labentia. Transformaciones, cambios y alteración en las ciudades bispanorromanas entre el siglo II y la tardoantigüedad. Uncastillo, 2017, pp. 345-374.

Andreu, J.; Romero, L. y Montoya, R.: "Los Bañales (Uncastillo, Zaragoza): ciuitas augústea", Anales de Arqueología Cordobesa, 25-26, 2014-2015, pp. 49-70.

Bellinger, A. R. y Alkins, M.: Victory as a coin type. New York, 1964.

BELTRÁN ForTes, J.: "Un monumento romano dedicado a la Victoria en el Museo de Antequera", Mainake, 4-5, 1983, pp. 227-236.

Beltrán Fortes, J.: Las arae de la Baetica. Málaga, 1988.

Beltrán Fortes, J. y Stylow, A. U.: "Un aspecto del culto imperial en el suroeste bético: el "puteal" de Trigueros (Huelva), un altar dedicado a Augusto", en Nogales, T. y GonzÁlez, J. (eds.): Culto imperial: política y poder. Roma, 2007, pp. 239-250.

Carvalho, H.; Encarnação, J. D.; Martins, M. y Cunha, A.: "Altar romano encontrado em Braga", Forum, 40, 2006, pp. 31-41.

Castillo, M. ${ }^{a}$ J.: "Una dedicatoria a las Matres en Badarán (La Rioja)", HAnt., 23, 1999, pp. 137-141.

DarWall-Smith, R.: Emperors and Architecture: A Study of Flavian Rome. Bruxelles, 1996.

FEARS, J. R.: "The theology of Victory in Rome: approaches and problems", ANRW 2, 17.2, 1981, pp. 736-826.

Fishwick, D.: "The Imperial Cult in Roman Britain", Phoenix, 15-4, 1961, pp. 213-229.

FuCHS, M.: Untersuchungen zur Ausstattung römischer Theater in Italien und den Westprovinzen des Imperium Romanum. Mainz, 1987.

GAGÉ, J.: "Un thème de l'art impèrial romain: la Victoire d'Auguste", MEFRA, 49, 1932, pp. 61-92.

Galimberri, A.: "The Emperor Domitian", en Zissos, A. (ed.): A Companion to the Flavian age of Imperial Rome. Chichester, 2016, pp. 97-99.

GAMER, G.: Formen römischer Altäre auf der Hispanischen Halbinsel. Mainz, 1989. 
JAVIER ANDREU PINTADO Y LUIS ROMERO NOVELLA UN ALTAR CILÍNDRICO A LA VICTORIA EN EL FORO DE LOS BAÑALES DE UNCASTILLO (ZARAGOZA, ESPAÑA)

García y Bellido, A.: Esculturas romanas de España y Portugal. Madrid, 1949.

GERGEL, R. A.: "An allegory of Imperial Victory on a cuirassed statue of Domitian", Record of the Art Museum. Princeton University, 45-1, 1986, pp. $2-15$.

HÖLSCHER, T.: Victoria Romana. Archäologische Untersuchungen zur Geschichte und Wesensart der römischen Siegesgöttin von den Anfängen bis zu Ende des 3. Jhs. n. Chr. Mainz, 1967.

Jordán, Á. A., y ANDREU, J.: «Un nuevo conjunto epigráfico en el foro romano de Los Bañales (Uncastillo, Zaragoza)", AEspA, 86, 2014, pp. 243-255.

KePPIE, L.: "Legiones II Augusta, VI Victrix, IX Hispana, XX Valeria Victrix", en Le Bohec, Y. y Wolff, C. (eds.): Les Légions de Rome sous le HautEmpire. Tome I. Lyon, 2000, pp. 25-37.

LuZÓN, J. M. ${ }^{a}$ : "Die neuattischen Rund-Aren von Italica”, MM, 19, 1978, pp. $272-289$.

Maqueda, R.; Luque, M.; Andreu, J. y Romero, L.: "Princeps resurgens: archaeological research and photogrammetric documentation in the study of a Roman thoracata statue of Los Bañales (Uncastillo, Zaragoza)", Virtual Archaeology Review, 6-13, 2015, pp. 65-71.

MoraWIECKI, L.: "The symbolism of Minerva on the coins of Domitian", Klio, 59, 1-2, 1977, pp. 185-194.

Navarro, M.: Perfectissima femina. Femmes de l'élite dans l'Hispanie Romaine. Bordeaux, 2017.

Nicolini, G.; Domergue, C.; Nony, D. y García-Bellido, A.: "Les fouilles de la Casa de Velázquez à Belo-Bolonia (Cádiz) en 1967 (Variété)", MCV, 4, 1968, pp. 393-40.

Nogales, T.: "La escultura", en Dupré, X. (ed.): Las capitales provinciales de Hispania. 2. Mérida. Colonia Augusta Emerita. Roma, 2004, pp. 113129.

NoREÑA, C.: Imperial Ideals in the Roman West. Representation, circulation, power. Cambridge, 2011.

Paladino, I.: Fratres Aruales. Storia di un collegio sacerdotale romano. Roma, 1988.

PerEA, S.: "El culto a la Victoria Augusta en Roma y en la Hispania altoimperial,, en HERNÁNDEZ GuERRA, L. (ed.): El mundo religioso hispano bajo el Imperio Romano. Pervivencias y cambios. Valladolid, 2007, pp. 221-235.

Ramallo, S. F.: "Drei neuattische Rundaltäre aus dem Theater von Cartago Noua (Cartagena, Spanien)", Archäologische Anzeiger, 4, 1999(a), pp. 523-542. 
Ramallo, S. F.: El programa ornamental del teatro romano de Cartagena. Madrid, 1999(b).

Rodríguez Oliva, P.: “Un ara romana de Málaga”, Jábega, 5, 1976, pp. 77-80. Romero, L.: "La basílica del foro de Los Bañales (Uncastillo, Zaragoza)", Habis, 48, 2017, pp. 113-131.

Romero, L.: "The roman forum of Los Bañales (Uncastillo, Zaragoza): Building, remodelling and reutilisation of a forum from the conuentus Caesaraugustanus", en 19th International Congress of Classical Archaeology (Bonn, 2018), en prensa, s. pp.

Romero, L. y Andreu, J.: "El programa escultórico del foro de la ciudad romana de Los Bañales: novedades y aspectos iconográficos, programáticos e históricos", en Márquez, C., y OJEDA, D. (eds.): Escultura romana en Hispania. VIII. Córdoba, 2018, pp. 365-378.

Romero, L.; ANDreu, J. y GABALDón, M.: "Un thoracatus imperial en Los Bañales (Uncastillo, Zaragoza)", Zephyrus: revista de Prehistoria y Arqueología, 73, 2014, pp. 197-216.

SCHERF, J.: "Victoria", en Der Neue Pauly. Enzyklopädie der Antike. Band 12/2. Stuttgart-Weimar, 2002, p. 190.

STANDing, G.: "The Claudian Invasion of Britain and the Cult of the Victoria Britannica", Britannia, 34, 2003, pp. 281-288.

Suess, J.: Divine Justification: Flavian Imperial Cult. Oxford, 2011.

Tuck, S. L.: "The origins of Imperial Hunting Imagery: Domitian and the Redefinition of Virtus under the Principate", Greece E Rome, 52-2, 2005, pp. 221-245.

Ventura, Á.; Andreu, J. y Romero, L.: "Equites del ala Tauriana al servicio de Roma: los Sempronii del oppidum de Los Bañales (Hispania citerior)", Gladius, 38, 2018, pp. 35-45. 